\title{
EVOLUTION OF THE YOUTUBE PERSONAS RELATED TO SURVIVAL HORROR GAMES
}

\author{
Francesco Toniolo Catholic University of Milan
}

\begin{abstract}
The indie survival horror game genre has given rise to some of the most famous game streamers on YouTube, especially titles likes Amnesia: The Dark Descent (Frictional Games 2010), Slender: The Eight Pages (Parsec Productions 2012), and Five Nights at Freddy's (Scott Cawthon 2014). The games are strongly focused on horror tropes including jump scares and defenceless protagonists, which lend them to displays of overemphasised emotional reactions by YouTubers, who use them to build their online personas in a certain way. This paper retraces the evolution of the relationship between horror games and YouTube personas, with attention to in-game characters and gameplay mechanics on the one hand and the practices of prominent YouTube personas on the other. It will show how the horror game genre and related media, including "Let's play" videos, animated fanvids, and "creepypasta" stories have influenced prominent YouTuber personas and resulted in some changes in the common processes of persona formation on the platform.
\end{abstract}

\section{KEY WORDS}

Survival Horror; Video Game; YouTube; Creepypasta; Fanvid; Let’s Play

\section{INTRODUCTION}

Marshall \& Barbour (2015, p. 7) argue that "Game culture consciously moves the individual into a zone of production and constitution of public identity". Similarly, scholars have studied - with different foci and levels of analysis - the relationships between gamers and avatars in digital worlds or in tabletop games by using the concept of "persona" (McMahan 2003; Waskul \& Lust 2004; Isbister 2006; Frank 2012). Often, these scholars were concerned with online video games such as World of Warcraft (Filiciak 2003; Milik 2017) or famous video game icons like Lara Croft from the Tomb Raider series (McMahan 2008). The list can be extended by including those scholars who have studied similar issues yet without relying on the concept of persona (such as Nephew 2006; Lebowitz \& Klug 2011; Burn 2013; Papale and Fazio 2018). With some exceptions (such as Milik 2017; Werning 2017), the notion of persona appears vague (Zagal and Deterding 2018), due to the complexity of its conceptual origin (Marshall et al. 2019). Moreover, the relationship between YouTubers or streamers and video games has been sometimes analysed in performative terms (Glas 2015; Newman 2016; Nguyen 2016; Burwell and Miller 2016) or included into broader analyses of online personas and micro-celebrities (Cocker and Cronin 2017). Nonetheless, ample space is still available for investigating the construction of YouTubers' and streamers' personas in relation to the video games they play. 
Even the most followed YouTubers remain micro-celebrities with micro-publics:

Personas can tap into a potentially massive audience and can feature tens, hundreds, thousands and even millions of individual followers, who are all nodes in a massively personal network. Micro-publics are micro, not in terms of scale, but with regards to the nature of the network that is regularly and privately updated by a central identity. (Moore et al. 2017)

Micro-celebrities are still celebrities, and an important object of analysis for studies about personas:

...how we read celebrity from the position of Persona Studies is that celebrity represents a powerfully visible exemplification of persona: celebrities are public presentations of the self and they inhabit the active negotiation of the individual defined and reconfigured as social phenomenon. (Marshall \& Barbour 2015, p. 9)

Gaming YouTubers are among the most followed micro-celebrities on the platform and, therefore, it is useful to study the evolution of their online personas with particular attention to the evolution of their personas' narrations (Holler and Klepper 2013) diachronically and in three different types of YouTube video categories: the "Let's play", animated fanvids, and "creepypastas". These types of videos, which feature survival horror games, show different connections between gameplay, in-game avatars, and YouTuber's persona narration.

The diachronic approach employed in this article allows us to see how the perception of authenticity has changed over time: "As emerging genres develop enough to have their own norms, tropes, and dedicated followers who become 'genre experts,' some kinds of posts become so familiar that they appear unoriginal or inauthentic" (McRae 2017, p. 14). By drawing research into the evolutionary history of YouTube, the article examines how popular YouTube personas became linked to horror video games and the survival subgenre in particular. As Rune Klevjer (2006) pointed out, in video game studies there has been a clear disconnection between investigations of video games in general and studies on specific games genres. Almost fifteen years later, the quantitative disparity is still clearly present although the situation appears to be much more multifaceted. However, when reporting the described lack of studies on video game genres, Klevjer indicated horror as an exception. Bernard Perron's works on horror games, still embryonic at the time (Perron 2005), contributed to the expansion of the topic (Perron 2009, 2018 ) and was accompanied by studies including Ewan Kirkland $(2009,2010,2011)$ and Tanya Krzwinska (2009 and 2013). There is a wider tradition of video game studies on horror than on other genres, therefore it is easier to retrace how changes in this tradition have influenced YouTuber persona narration by observing how the analysis of survival horror streaming and related media has developed over time.

The research phase behind this work followed the principles put forward by Pertti Alasuutari (1995, p.165) concerning the need to observe a phenomenon as a whole, from different angles and perspectives, without dwelling on what is considered useful a priori only. With regard to the more ethnographic components of the research, the general recommendations of Hine (2000) were taken into account as well. A qualitative approach was adopted, based on moderate participatory observation (DeWalt \& DeWalt 2010). Such observation, however, was conducted on a group that was sufficiently extensive and varied to provide an exhaustive image of the phenomenon. The videos were collected and viewed from the beginning of 2016 to April 2018: notes of varying lengths were taken on almost 2200 (precisely 2173) of these videos. Around that number, a point of data saturation and theoretical 
saturation was reached (Fusch \& Ness 2015; Saunders et al. 2018): further videos would not have opened new research perspectives, nor would it have added significant elements to perspectives already identified. In the case of live streaming, since most often performances were impossible to follow live, they were retrieved later when available. However, an attempt was made, at least for short periods, to follow that daily or periodic ritualism offered by certain channels, which influence the temporality of the viewers (Newman 2016, p.286).

The results are presented through a sampling methodology, divided into three main time periods. The first one, spanning from the birth of the platform (2006) to 2009, constitutes the embryonic stage of gaming on YouTube that was not fully developed and the first systematic studies dedicated to this platform (Burgess \& Green 2009) hardly mention it. A second phase, between 2010 and approximately 2014, witnesses the establishment of many well-known YouTuber gamer personas and the systematisation of the various types of horror genre content. Finally, the third phase features a process of naturalisation and institutionalisation, in addition to the growth of streaming practices, especially alongside Twitch.tv, which in some cases replaces YouTube. In this article, this diachronic partition constitutes the starting point and remains as a common thread but is not explicit in the subdivision of the remainder of the article. Instead, the structure of the following looks instead to the three categories of horror game related content, including Let's Plays, animated fanvids, and creepypastas. For the emotional description of the YouTuber persona's reactions, the emotion categories of Chen et al. (2017) were adopted as a general basis for analysis and were combined with more theoretical and video game based approaches (Isbister 2016).

\section{SURVIVAL HORROR “LET’S PLAY” VIDEOS}

In the years immediately preceding the success of the YouTube platform, horror video games witnessed a progressive turn towards action, especially in Western productions (Pruett 2012). Despite abandoning the action component, these video games obtained a great success and became a constant presence on YouTube. Three of the most famous are Amnesia: The Dark Descent (Frictional Games 2010), Slender: The Eight Pages (Parsec Productions 2012) and Five Nights at Freddy's (Scott Cawthon 2014). These games were released in a period of growth of gaming on the YouTube platform, and several YouTubers achieved notoriety thanks to one or more of them. Amnesia: The Dark Descent, in particular, is closely linked to the career of PewDiePie (Smith et al. 2013), Markiplier, and Favij (one of the most famous Italian YouTubers; for the gaming scene of YouTube in Italy see Toniolo 2020).

Amnesia: The Dark Descent is not the first survival horror created by Frictional Games, as it follows the trilogy Penumbra: Overture (Frictional Games 2007), Penumbra: Black Plague (Frictional Games 2008), and Penumbra: Requiem (Frictional Games 2009). During the Penumbra trilogy release period, gaming on YouTube was still at an embryonic stage. Channels specifically dedicated to "Let's play" were emerging and videos on the topic were growing. Nevertheless, critical mass had not yet been reached, and the platform was dominated by other types of videos, such as vlogging (Burgess \& Green 2009). A diachronic retrospective of the videos related to Penumbra shows hints of the change that would come shortly afterwards with Amnesia: The Dark Descent. In addition to trailers, in 2007 some videos belonging to the "how to" category (such as jazzkomp 2007 and KPIQA 2007) appeared, alongside videos of trolling (KirmiZ 2007) and short videos on certain parts of the game (such as l3ks1 2007 and Altraum 2007). Apart from a low visual quality, what can be detected immediately is a complete absence of vocal commentaries: whenever the YouTuber inserted thoughts and opinions, these were in the form of superimposed words or text boxes. Two years later, the situation was already very different and videos from 2009 related not only to the two subsequent chapters of the saga but 
also to the first Penumbra are much more numerous and differentiated. There still were short videos aimed at showing specific elements (such as Easter Eggs), accompanied by episodic gameplay with an audio commentary by the YouTuber horror game personas including TheScarlettears 2009, ColdTrix8 2009, and Helloween4545 2009. These first vocal commentaries sound more surprised than frightened, repeating sentences like "What the hell is that?", in a puzzled tone of voice when monsters appear. However, in other videos, comments remained textual or absent (such as Captain Perfect 2009). However, the majority of gameplay videos dedicated to Penumbra followed the release of Amnesia: The Dark Descent. Markiplier's 2012 gameplay video, for example, features a more energetic and varied audio commentary, in which the YouTuber reacts to the first appearance of the monster in a defiant tone of voice (2012a), then keeps screaming in a frightened way while the monster chases him (2012b).

In a gameplay video from the following year, the YouTuber FavijTV (2013), showed his live reactions in the corner of the screen via webcam. At the beginning of the video, Favij said that he already knew the initial part of Penumbra: Black Plague, because the previous year he had played it on another channel (NiKyBox 2012, in which his reactions were not visible) to start his series "Giochi nel Buio" (Games in the Dark). Therefore, he said that he expected not to experience "exaggeratedly incredible heart attacks during this first episode" (FavijTV 2013, minute 1:42). At the monster's first appearance, he has a moderate reaction, and he says he did not remember that moment. However, at the second appearance, despite being prepared, he begins to cry out. Comparing this performance with his previous gameplay of the same game (NikYBoX 2012), his reactions are louder and more blatant. It can also be noted that, in line with the most frequent curses of Italian YouTubers (Kurpiel 2016), he often uses the expression "cazzo!" and other forms of swearing (Fägersten 2017). Literally, "cazzo" is a swear word for "penis", but it can also be used similarly to the English "fuck!". Following another recurrent practice (Kurpiel 2017), he also assigns a nickname to the monster, calling it "Piff". As this example shows, reactions to horror video games tend to be increasingly spectacularised over time.

Horror genre YouTuber personas look for the most frightening video games and record their first playthrough on video to capture what they call "natural" reactions. Amnesia: The Dark Descent, which helped the development of this horror desire on YouTube, is part of this evolutionary phase. As the game's creators pointed out, the relationship between YouTube and Amnesia: The Dark Descent has been particularly beneficial for both sides: not only did the game contribute to the birth of many successful YouTubers and increase its sales thanks to them, but also contributed to the evolution of the survival horror genre and the "Let's play" video format:

"I think Amnesia got a lot of free PR because of "Let's Play" videos, but I also think that Amnesia opened people to a new style of 'Let's Play,"' Frictional Games creative director Thomas Grip told me. "Normally, games are very skillbased. You need to be concentrated and play a certain way to play 'properly.' But with horror games, the aim is not to win, but rather to get immersed. That gives a lot more space for 'Let's Players' to put on a show, either by being very scared or just fooling about. On top of that it is really fun to see someone scared for some reason. (Maiberg 2015; see also Suvilay 2018:88 for the focus on narrative immersive elements in Amnesia: The Dark Descent).

And:

Speaking to VICE Gaming in October 2014, The Dark Descent's creative director, Thomas Grip, explained that there's 'a lot to be done in making horror more personal and thought-provoking', and that 'a game could be 
terrifying with a bare minimum of features'. And that's something indies have been doing while the more publicized, more predictable alternatives take their turns at being the open-world game of the moment: maximizing impact while maintaining modest budgets, development mirroring the gameplay of survival-horror games themselves in using few resources but delivering chills aplenty. [...] The popularity of horror in the indie-games field owes much to YouTube, to gamers posting footage of themselves getting terrified in the company of these low-budget, one dare say more intimate experiences - the first-person perspective certainly encourages a deeper bond between player and protagonist. (Diver 2016, pp. 56-57)

Other commentators, however, would see this fruitful relationship between YouTuber and horror video games as harmful for the genre:

Everyone and their mother wanted to craft a masterful horror game that would catch the attention of the likes of PewDiePie or Markiplier (and possibly get them rich in the process!). This led to the quality of these games deteriorating rapidly as desperation and saturation set in, coupled with the fact that these designers knew nothing about horror game design except that "jumpscares get views on YouTube, and views on YouTube get me popular!" It became rare to see horror games that were genuinely well-crafted and gave you an unsettling feeling that something was wrong. (Mathur 2016)

A few years after Amnesia: The Dark Descent, another horror video game had a strong impact on the YouTubers' performances, Five Nights at Freddy's (Scott Cawthon, 2014). This video game was born practically by chance from the encounter between a video game for children and a YouTuber, and, thanks to YouTube, spread very quickly. In May 2014, the critic and YouTuber Jim Sterling published a video in which he analysed the trailer for Chipper \& Sons Lumber Co. (Scott Cawthon 2013), a children's video game starring a beaver. Sterling (2014) harshly criticised the character design, which appeared uncanny and disturbing instead of being cute and attractive. In the beginning, apart from this video, nobody paid much attention to this video game. However, in the August of the same year, Scott Cawthon published Five Nights at Freddy's. The video game, which obtained a wide and immediate success, presented some frightening animatronics as enemies. These iconic figures constitute one of the most interesting elements of the video game, thanks to the YouTubers' reactions to the unexpected assaults of the creatures. In an interview, when asked about the origin of these scary animatronics, Scott Cawthon answered:

I'd made a family friendly game about a beaver before this, but when I tried to put it online it got torn apart by a few prominent reviewers. People said that the main character looked like a scary animatronic animal. I was heartbroken and was ready to give up on game-making. Then one night something just snapped in me, and I thought to myself- I bet I can make something a lot scarier than that. (Couture 2014)

From the beginning, Five Nights at Freddy's "Let's play" videos gained a large number of views. Markiplier's first gameplay dedicated to this video game (Markiplier 2014) was published just four days after the release of the first version of Five Nights at Freddy's on August $12^{\text {th }}, 2014$. In his gameplay "he screams 94 times in a 17-minute-long video, not articulating words properly, and he often gets perplexed, verbalizing 10 no's [sic] in a row, when most startled" (Pietruszka 2016:64). The YouTuber highlights from the title how scary Five Nights at Freddy's is ("WARNING: SCARIEST GAME IN YEARS", all in capital letters). 
PewDiePie's video (2014), published a few days later (on August 22 ${ }^{\text {nd }}$ ), shares several traits with the one by Markiplier (including the title in capital letters). During a particular jump scare (at minute 5:20), the YouTuber abandons English for a moment and expresses a Swedish curse. For a moment he seems to break character, returning to being Felix Kjellberg, because a few days before he had declared (Kjellberg 2014) that his use of English was closely linked to his online persona, PewDiePie. So, the use of Swedish appears as a sort of guarantee of the authenticity of his fear. Authenticity is particularly important for YouTubers because they and other micro-celebrities sometimes struggle to appear authentic in their formats (Jerslev 2016; McRae 2017; Cunningham \& Craig 2017). However, jumpscares become predictable quickly, and at the second or third video on the same game, YouTubers tend not to react as much as before, shifting attention to other elements, if possible. In this perspective, Five Nights at Freddy's does not rely entirely on jumpscares and has proved to be popular in the long run. The game hides several secrets and suggestions about events that have never been fully clarified and are discussed by its fans in articulated theories on the lore. The YouTube channel, The Game Theorist, has made numerous videos in which the mysteries of Five Nights at Freddy's are analysed and discussed. Moreover, the lore of Five Nights at Freddy's returns in the other two categories presented here: fanvids and creepypastas.

The existence of another phenomenon is also noted: some video games directly mention YouTubers, either with internal references ${ }^{1}$ or by referring directly to them on the product description page $^{2}$. Although these direct references are not necessarily much effective, some video games continue to use these kind of elements.

\section{ANIMATED FANVIDS}

Between 2006 and 2008, several YouTube channels were born that made music videos and animated parodies featuring the characters from Resident Evil as protagonists: not only the heroes of the saga but also - and sometimes above all - their antagonists. Among those first channels was ShadowLeggy, by an American YouTuber and animator.

Her first videos (ShadowLeggy 2006, 2007) combined popular songs - such as the English version of Dragostea Din Tei (O-Zone 2003) or I'm So Excited (The Pointers Sisters 1982) - and animated drawings depicting Resident Evil characters performing actions according to the lyrics of the song or simply dancing and singing. The characters followed the joyful atmosphere of the songs, while maintaining their role, at least in part: zombies tore apart the living and heroes shot monsters, but blood could be used to draw hearts on a wall and calls to secret agents were declarations of love. Progressively, other content creators emerged who made similar videos, combining characters from Resident Evil (and sometimes other series, such as Silent Hill) and popular songs. In some cases, for example, the characters reinterpreted famous Disney songs (like in DirectorBen92 2007), in others there were bizarre pairings (like the Dutch version of the song Barbie Girl in jeanetteRyokuX 2007) or popular memes of that year (ShadowLeggy 2009). There were also choral videos such as heeminhyman (2008), in which several people animated different parts of a story in which Leon Kennedy from Resident Evil was the protagonist of "Weird Al" Yankovic's song Albuquerque (1999).

Resident Evil was an established series long before the creation of YouTube. However, many of the most successful horror video games of the following years - like those mentioned above - were also used in a similar way by some YouTubers, who also included themselves as characters in their animated videos. The most popular animated videos dedicated to Amnesia: The Dark Descent contain the character of PewDiePie and constitute a sort of expansion of his "Let's play" videos. Similar patterns are equally traceable in the period that preceded the rise of 
the most successful gamers' channels. Since those years, several creators, such as ShadowLeggy and DirectorBen92, had been including their drawn alter egos as short cameos in several videos. Their videos showed new connections between the characters of a series (like protagonists and antagonists from Resident Evil), and between those characters and the YouTuber's personas. Moreover, unlike "Let's play" players, these content creators neither show themselves nor speak in their videos: it is through the animated versions that they build and perform their online personas on YouTube. The relationship between their YouTube personas and villains in animated videos seems to have anticipated a trend (of connections with survival horror enemies) that grew later with video games like Five Nights at Freddy's.

The evil animatronics in Five Nights at Freddy's are numerous, all different in appearance and personality, immediately recognisable and distinguishable from each other, as iconic as many famous cinematic monsters (Bycer 2015). Their uncanny appearance places them somewhere between scary and friendly, either of which can be easily developed. Sexualised versions of animatronics are also easy to find, even on platforms such as YouTube or DeviantArt. This fact, however, seems hardly surprising. Several other characters from products for children or teenagers have also been sexualised in online communities, and the animatronics of Five Nights at Freddy's, as robotic animals, are easily linked to "furry" fandom and the erotic aspects of that animal costume play. Analysis of "friendly" videos, many of them (animated in two or three dimensions) with millions of views, show animatronics as kind and welcoming (for example Typhoon Cinema 2015 and FURR Animations - FNAF School of Animatronics 2015).

In some cases, new formats were born from the idea of a particular channel, which set a standard imitated by others. An example of a new format is the series of videos "My Dear Friend" (such as Blu's Studio 2018; Smoke the Bear 2018; Jaze Cinema 2018). Many videos tell a story of friendship between an animatronic and a little girl (more rarely a boy), often linked to a temporal element: sometimes, the child finds the animatronic damaged and, remembering the happy days spent together, tries to fix it; in other cases, it is the animatronic who remembers the child and driven by those memories, goes to look for her, bring her a gift or save her from some danger. Even when these robots are presented as dangerous, they do not harm the children who have been their friends. Similar videos existed prior to the games release, however, their popularity increased over the following four years.

Returning to "Let's play" players, in many cases they start developing their relationships with the enemies in their "Let's play" videos: they assign nicknames to monsters, talk directly to them (asking them to be good, to go away, to try to be friends) and they perform a series of other in-game actions to familiarise themselves with these opponents. Later on, if their interest for one of the video games persists, the YouTubers tend to upload other types of content including animations and music videos in which they develop a different relationship with the monsters. For example, YouTuber Jacksepticeye (2015) confronts a sexy version of the animatronic Toy Chica, Game Grumps (2018) appear as characters in Doki Doki Literature Club! (Team Salvato 2017) and PewDiePie (2016) takes a selfie with a dead body in Outlast 2 (Red Barrels 2017). This pattern repeats for many horror video games and games with horror elements, including Doki Doki Literature Club! to Granny (Dvloper, 2017), Baldi's Basics in Education and Learning (Micah McGonigal 2018), Hello Neighbor (Dynamic Pixels 2017), Spooky's Jump Scare Mansion (Lag Studios 2014), and Bendy and the Ink Machine (TheMeatly Games 2017). 


\section{CREEPYPASTAS AND Video GAMES}

Creepypastas are horror-related stories that are spread via the internet and are combined with survival horror video games by YouTuber personas in two ways: video games as creepypastas and video games about creepypastas. Video games as creepypastas are disturbing stories based on pre-existing video games. A famous example is Ben Drowned (also known as Majora's Mask Creepypasta), a scary story behind a particular ROM cartridge of The Legend of Zelda: Majora's Mask (Nintendo 2000). The story of this "corrupted" copy was originally posted on 4chan's /x/ (a message board dedicated to the paranormal) and included links to YouTube videos (the first of which is Alex Hall 2010) to support the claim of truthfulness of the story, and a text about the disturbing repercussions that the game was said to be having on the real life of its player. Creepypastas of this kind, including the NES Godzilla Creepypasta (based on the video game Godzilla, Monster of Monsters, Compile 1988) and the Slender Man case, use different media to provide 'evidence' of their authenticity such as screenshots and YouTube videos. The YouTuber personas that make use of this form of creepypasta are often built using voice-overs that narrate the events in a slow and theatrical manner Many YouTubers have made videos dedicated to preexisting horror-themed stories, sometimes also translating the original text into other languages. In other cases, the creepypastas appeared directly on YouTube. However, many of these stories talk about video games that are not actually playable.

Playable creepypastas are video games about creepypastas and accompanied by an external narrative. Video games about Slender Man, for example, and other characters such as Jeff the Killer were created by pre-existing horror stories. Slender Man is a popular usergenerated internet phenomenon from 2009 when a Something Awful (2009) user posted two modified images in response to a "create paranormal images" contest. In these black and white images depicting a group of children, a silhouette of a tall, thin, and faceless man had been inserted in the background. The creature, called "Slender Man", spread via 4chan's /x/ and then other sites and platforms (see Chess 2012, 2015; Freitas and Amaro 2016; Smith 2017; and Peck 2017). These playable creeypastas, such as the Slender Man video game, are included under the label of "indie games", which is a type of video game development that is linked to experiential design practices (Marshall et al. 2019, p.167-168), which leads to another group of YouTube videos.

Over the years, a large number of YouTubers have talked about creepypastas through "Let's play" videos, stories, theories, and crossovers. For example, the first traces of Sad Satan (anonymous 2015) appeared on YouTube in 2015 as a "Let's Play" video (in a channel named Obscure Horror Corner), and presented a new way to exploit the potential of gaming videos for creepypastas and horror stories in general (Peters 2018). According to the (no longer present) description of the video, this video game would have been downloaded from the deep web via an onion link that was reported there. The video lacks voice-over commentary, and the game is almost incomprehensible. In a first-person view, the player moves along several almost completely dark corridors in which sometimes images appear, including the Japanese serial killer Tsutomu Miyazaki, Margaret Thatcher, and a statue of Lady Justice. The musical soundtrack is intermittent, sometimes interrupted by footsteps, and where present, it is made up of repetitive and disturbing sounds, alternating with dialogue played backwards. In a few days, news of the game spread, and the onion link (a deep web URL) provided proved to be a fake. A 4chan's anonymous user posted on /x/ a link to download what he/she defined as the "Real Sad Satan", different from the one shown on Obscure Horror Corner. However, the "Real Sad Satan" proved to contain gore, child pornography, and malware. ${ }^{3}$ The Obscure Horror Corner video about Sad Satan was a silent creepypasta on YouTube, which relied on external elements (like its onion link) to build an aura of its own. However, it soon evolved into a more 
accessible experience, as a new version of the game spread first through 4chan and then Reddit. Along with the "Real Sad Satan" came more traditional "Let's play" videos, in which a YouTuber would try the video game, comment about it, and show his reactions. However, the result differed from many other "Let's play" videos and creepypastas. Sad Satan hinders the activity of the player and the commentator in every way: it is an experience of emptiness and nothingness (Rodríguez Serrano 2017).

After Sad Satan, YouTube-related creepypastas returned to more narrative forms. Perhaps, the most relevant case that emerged after Sad Satan is Petscop, a game specifically made for a series of videos. The first video of Petscop was uploaded on a channel with the same name (Petscop 2017) by "Paul", who was the voice of the "Let's play" videos. The persona created by Paul was not the typical YouTuber who addresses an audience at large, but someone speaking directly to a single person, a friend, to whom he intended to show the strange video game he had found. In so doing, Paul generated a different kind of intimacy where audience can enjoy overhearing a conversation and have to perform further interpretative work to decipher Paul's references to facts likely to be known to his alleged interlocutor only (Peters 2018). These videos were born as a source of information about Petscop, an unfinished PlayStation video game from 1997 made by a fictional company called Garalina. Petscop's narrator, "Paul" hides himself to fake authenticity, to convey the idea that he has no interest in showing himself, because he is making those videos for a friend only. The preparatory work of the anonymous creator to make Petscop is remarkable; after all, fabrication can be considered a form of work (Marwick 2013). Building on and surpassing the lesson of Sad Satan, Petscop is one of the most peculiar examples of revolutionising and revitalising a YouTube format centred on one kind of persona.

The vitality of the creepypasta model is also shown by the success achieved by video games that recover the modus operandi of these stories such as Undertale (Toby Fox 2015), Doki Doki Literature Club!, and Pony Island (Daniel Mullins Games 2016). These games depict horror linked to technology, the suffering or death inflicted on friendly and innocent characters, the corruption of the code (and of the graphic), the insertion of photorealistic elements, the direct interaction with the player, and the general idea of an obscure truth beneath the surface.

\section{CONCLUSION}

The role played by YouTuber personas in the evolution process of horror games emerges from a series of elements that have been examined in the diachronic investigation of this article. To summarise, we first examined the link between the construction of the YouTuber personas and the survival horror video games genre.

In general, survival horror and YouTubers can constitute a combination capable of generating good performances even outside the cases of instantaneous and explosive success. The creator of Emily Wants to Play (Shawn Hitchcock 2015), for example, has publicly Acknowledged the contribution made by YouTubers and streamers to the success of his video game: "They played a major role in the success of Emily Wants To Play and it's a "win-win" situation. Emily brings new viewers, a larger view count, and more "likes" to their channel and it brings new fans to Emily" (Tisdale 2016). In addition to the direct increase in sales, the popularity has allowed the game to see numerous ports made on consoles in a short time.

The YouTuber's activity is a creative work, linked more to performance than representation (Lee 2015), and is a form of the gâmeur's practices of exploring and presenting indie games (Marshall et al. 2019, p. 171-172). Their activity leads to a continuous negotiation for the search for authenticity (Jerslev 2016; McRae 2017; Cunningham and Craig 2017) in 
which the desire is to offer the most advantageous representation of the YouTube persona. Their practices are characterised by a very strong spreadability (Jenkins, Ford, and Green 2013): they are adaptable and reconfigurable according to the needs of various users. They structure a co-creative, participatory persona who is actively promoting themselves and the video game: a synergistic spreadability, therefore, in which developers, YouTubers, and players / spectators can participate. This synergy is not always realised, and sometimes is hardly achievable, but rhetorically is often presented through youtubers strategies and discourses.

\section{ACKNOWLEDGEMENTS}

Parts of this article are updated, expanded, and translated excerpts from my PhD thesis.

\section{END NOTES}

1. For example: One Night (Rinat Mirzasalikhov 2014) contains a collage of YouTubers including the Russian Kuplinov, and Epsilon corp. (Alexandr Kataev 2016) has an image of PewDiePie inside a locker. Run Rooms (IDALGAME 2017), instead, has placed on the wall of a room the photos of YouTubers who have already recorded one or more videos about the game. Even the trailer on Steam is a group of clips from various YouTube channels.

2. The Steam page of Insanz - Retro Survival Horror (SimplexGameStudio 2015), for example, says that: «THE GAME CONTAINS SCENES MAY BE KEPT AND CRAZY TO BRING LAUGH. MAY Become a YOUTUBE VIDEO CREATE. When side effects, contact your doctor or pharmacist!» [sic].

3. For a more detailed summary of this story, see the related Reddit thread (u/BrokenLink100 2015).

\section{WORKS CITED}

Alasuutari, P 1995, Researching Culture. Qualitative Method and Cultural Studies, SAGE, London. Alexandr, K 2016, Epsilon corp., PC, Alexandr Kataev.

Altraum 2007, Penumbra Overture Episode 1 red burning 1, 05 July, YouTube, retrieved 26 August $2020<$ https://www.youtube.com/watch?v=NKkjSyfU2fQ>.

Blu's Studio 2018, [FNAF/SFM] My Dear Friend Funtime Foxy (FNAF Sister Location animation), 05 January, YouTube, retrieved 26 August 2020

$<$ https://www.youtube.com/watch?v=lkuxCcSgwgA>.

Burgess, J \& Green, J 2009, YouTube: Online Video and Participatory Culture, Polity Press, Cambridge.

Burn, A 2013, 'Role-Playing', in M.J.P Wolf \& B Perron (eds.), The Routledge Companion to Video Game Studies, Routledge, London - New York, pp. 241-250.

Burwell, C \& Miller, T 2016, 'Let's Play: Exploring literacy practices in an emerging videogame paratext', E-Learning and Digital Media, vol. 13, no. 3-4, pp. 109-125.

Bycer, J 2015, 'Examining The Five Nights at Freddy's Experience', 03 August, Gamasutra, retrieved 26 August 2020

<https://www.gamasutra.com/blogs/JoshBycer/20150803/250286/Examining_The_Fi ve_Nights_at_Freddys_Experience.php>. 
Captain Perfect 2009, Penumbra Black Plague gameplay part 1, 28 November, YouTube, retrieved 26 August 2020 <https://www.youtube.com/watch?v=47y2TdsUew8>.

Cawthon, S 2013, Chipper \& Sons Lumber Co., PC, Scott Cawthon.

-2014, Five Nights at Freddy's, PC, Scott Cawthon.

Chen, Y-L., Chang, C-L. \& Yeh, C-S. 2017, 'Emotion Classification of YouTube Videos', Decision Support Systems, vol. 101, pp. 40-50.

Chess, S 2012, 'Open sourcing horror: the Slender Man, Marble Hornets, and genre negotiations', Information, Communication, \& Society, vol. 15, no. 3, pp. 374-393.

-2015, Who <3's Slendy? Making Sense of Slender Man Fandom, paper presented at Internet Research 16: The 16th Annual Meeting of the Association of Internet Researchers, pp. 21-24.

Cocker, H.L \& Cronin, J 2017, 'Charismatic authority and the YouTuber: Unpacking the new cults of personality', Marketing Theory, vol. 17, no.4, pp. 455-472, https://doi.org/10.1177/1470593117692022

ColdTrix8 2009, Let's Play Penumbra Overture Part 1 Mines and blocked entrances, 30 August, YouTube, retrieved 26 August 2020 <https://www.youtube.com/watch?v=ibsXjDcNyHw>.

Compile 1988, Godzilla: Monster of Monsters, NES, Toho.

Couture, J 2014, IGM Interviews - Scott Cawthon (Five Nights at Freddy's), 03 september, Indiegamemag, <http://indiegamemag.com/igm-interviews-scott-cawthon-five-nightsat-freddys/>.

Cunningham, S \& Craig, D 2017, 'Being 'really real' on YouTube: authenticity, community and brand culture in social media entertainment', Media International Australia, vol. 164, no. 1, pp. 71-81.

Daniel Mullins Games 2016, Pony Island, PC, Daniel Mullins Games.

DeWalt, K.M \& DeWalt, B.R 2010 [2001], Participant Observation: A Guide for Fieldworkers. Second Edition, Rowman, Lanham.

DirectorBen92 2007, Resident Love, 01 September, YouTube, retrieved 26 August 2020 $<$ https://www.youtube.com/watch?v=n2jf8Tc5g0g>.

Diver, M 2016, Indie Games. The Complete Introduction to Indie Gaming, LOM Art, London.

Dvloper 2017, Granny, Android, Dvloper.

Dynamic Pixels 2017, Hello Neighbor, PC, tinyBuild.

Fägersten, K.B 2017, 'The role of swearing in creating an online persona: The case of YouTuber PewDiePie', Discourse, Context \& Media, vol. 18, pp. 1-10.

FavijTV 2013, UN INIZIO TERRIFICANTE!!! - Penumbra: Black Plague [in Webcam LIVE] | Parte 1, 02 March, YouTube, retrieved 26 August 2020 $<$ https://www.youtube.com/watch?v=2pAivtuE_mA>.

Filiciak, M 2003, 'Hyperidentities: Postmodern Identity Patterns in Massively Multiplayer Online Role-Playing Games', in M.J.P Wolf \& B Perron (eds.) The Video Game Theory Reader, Routledge, London - New York, pp. 87-102.

Fox, T 2015, Undertale, PC, Toby Fox.

Frank, J 2012, Role-Playing Game and Collectible Card Game Artists. A Biographical Dictionary, McFarland, Jefferson.

Freitas, C \& Amaro, M 2016, 'Slender Man: creepypasta, mimese e realidade', Temática, vol. 12, no. 1 , pp. 33-48.

Frictional Games 2007, Penumbra: Overture, PC, Frictional Games.

-2008, Penumbra: Black Plague, PC, Frictional Games.

-2009, Penumbra: Requiem, PC, Frictional Games.

-2010, Amnesia: The Dark Descent, PC, Frictional Games.

FURR Animations - FNAF School of Animatronics 2015, [FNAF SFM] School Of Animatronics: Full Animation Film (Original), 23 November, YouTube, retrieved 26 August 2020 $<$ https://www.youtube.com/watch?v=Pr4EzhrbUfl>.

Fusch, P.I \& Ness, L.R 2015, 'Are We There Yet? Data Saturation in Qualitative Research', The Qualitative Report, vol. 20, no. 9, pp. 1408-1416. 
Glas, R 2015 'Vicarious Play: Engaging the Viewer in Let's Play Videos', Empedocles: European Journal for the Philosophy of Communication, vol. 5, no. 1-2, pp. 81-86, http://dx.doi.org/10.1386/ejpc.5.1-2.81_1.

heeminhyman 2008, RE: Albuquerque (collab video), 12 June, YouTube, retrieved 26 August 2020 <https://www.youtube.com/watch?v=Wh25xQZFOVM>.

Helloween4545 2009, Let's Play Penumbra Overture (1 P 1), 02 March, YouTube, retrieved 26 August $2020<$ https://www.youtube.com/watch?v=MXyel4FXaOk>.

Hine, C 2000, Virtual Ethnography, SAGE, Thousand Oaks.

Hitchcock, S 2015, Emily Wants to Play, PC, Shawn Hitchcock.

Holler, C \& Klepper, M 2013 (eds.), Rethinking Narrative Identity: Persona and Perspective, John Benjamins Publishing Company, Amsterdam - Philadelphia.

Isbister, K 2006, Better Game Characters by Design. A Psychological Approach, Morgan Kaufmann Publishers, San Francisco.

- 2016, How Games Move Us. Emotion by Design, MIT Press, Cambridge (MA).

jacksepticeye 2015, Five Nights At Freddy's 2 Animation / Jacksepticeye Animated, 05 May YouTube, retrieved 26 August 2020

<https://www.youtube.com/watch?v=bqNzbkIHYF8>.

Jaze Cinema 2018, [FNaF 6/SFM] My Dear Friend \#2: Rockstar Bonnie, 15 July, YouTube, retrieved 26 August $2020<$ https://www.youtube.com/watch?v=Kagb5vLSUCg>.

jazzkomp 2007, Penumbra Overture How to kill the DOG, 10 April, YouTube, retrieved 26 August $2020<$ https://www.youtube.com/watch?v=PnxosjFRv_o >.

jeanetteRyokuX 2007, Resident evil remake can sing, 23 May, YouTube, retrieved 26 August $2020<$ <ttps://www.youtube.com/watch?v=yuq1Sj-_Lw>.

Jenkins, H, Ford, S \& Green, J 2013, Spreadable Media: Creating Value and Meaning in a Networked Culture, New York University Press, New York - London.

Jerslev A 2016, 'In the Time of the Microcelebrity: Celebrification and the YouTuber Zoella', International Journal of Communication, vol. 10, pp. 5233-5251.

Jim Sterling 2014, CHIPPER \& SONS LUMBER CO. - I'll Swallow Your Soul!, 08 May, YouTube, retrieved 26 August $2020<$ https://www.youtube.com/watch?v=GcvRx0Sx1Hc>.

Kirkland, E 2009, Resident Evil's typewriter: Horror videogames and their media, Games and Culture, vol. 4, no. 2, pp. 115-126.

-2010, 'Remediation, Analogue Corruption, and the Signification of Evil in Digital Games', in N. Billias (ed.), Promoting and Producing Evil, Rodopi, Amsterdam-New York, pp. 227-247.

-2011, 'Survival horrality: analysis of a videogame genre', The Irish Journal of Gothic and Horror Studies, vol. 10, pp. 22-32.

KirmiZ 2007, Penumbra Monster Fun!, 27 August, YouTube, retrieved 26 August 2020 $<$ https://www.youtube.com/watch?v=6sG9yuf5Cz4>.

Kjellberg, F. 2014, Felix "PewDiePie" Kjellberg (in English), 09 August, Sverigesradio, retrieved 26 August $2020<$ https://sverigesradio.se/sida/avsnitt/421641? programid=2071>.

Klevjer, R 2006, hc11: Genre Blindness, DiGRA Hardcore Column, retrieved 26 August 2020 <http://www.digra.org/hc11-rune-klevjer-genre-blindness/>.

KPIQA 2007, Penumbra overture lobo en escalera, 05 June, YouTube, retrieved 26 August 2020 <https://www.youtube.com/watch?v=h1qEGFY8NJo>.

Krzwinska, T 2009, 'Reanimating Lovecraft: The Ludic Paradox of Call of Cthulhu: Dark Corners of the Earth', in B. Perron (ed.), Horror Video Games. Essays on the Fusion of Fear and Play, McFarland, Jefferson, pp. 267-287.

-2013, 'Digital Games and the American Gothic: Investigating Gothic Game Grammar', Intersemiose, vol. 2, no. 4, pp. 291-310.

Kurpiel, R 2016, 'A Contrastive Analysis of Exclamations in Selected Italian and Polish Gaming Videos on YouTube', Zeszyty Naukowe Towarzystwa Doktorantów UJ Nauki Humanistyczne, vol. 15, pp. 73-90.

-2017, 'The stylistics of recontextualization in selected American, Italian and Polish gaming videos on YouTube', Młoda Humanistyka, vol. 8, no. 1, pp. 1-17. 
l3ks1 2007, penumbra gameplay, 23 May, YouTube, retrieved 26 August 2020 $<$ https://www.youtube.com/watch?v=MlkQ4hoa_EM>.

Lag Studios 2014, Spooky's Jump Scare Mansion, PC, Lag Studios.

Lebowitz, J \& Klug, C 2011, Interactive Storytelling for Video Games A Player-Centered Approach to Creating Memorable Characters and Stories, Focal Press, Oxford.

Lee, K 2015, 'Introduction: Personas at Work', Persona Studies, vol. 1, no. 2, pp. 1-13, https://doi.org/10.21153/ps2015vol1no2art500.

Maiberg, E 2015, Why Horror Games Are More Fun to Watch Than Play, 30 October, Motherboard, retrieved 26 August 2020 $<$ https://motherboard.vice.com/en_us/article/z43eb9/why-horror-games-are-morefun-to-watch-than-play>.

Marshall, D \& Barbour, K 2015, 'Making Intellectual Room for Persona Studies: A New Consciousness and a Shifted Perspective', Persona Studies, vol. 1, no. 1, pp. 1-11.

Marshall, D, Moore, C \& Barbour, K 2019, Persona Studies: An Introduction, Wiley Blackwell, Hoboken.

Markiplier 2012a, Penumbra: Black Plague / Part 1 / SHOT THROUGH THE HEART, 27 May, YouTube, retrieved 26 August 2020 $<$ https://www.youtube.com/watch?v=kAhZ4yfxG68\&>.

-2012b, Penumbra: Black Plague / Part 2 / SOMETHING'S FISHY, 27 May, YouTube, retrieved 26 August $2020<$ https://www.youtube.com/watch?v=J8D1EydOBZw>.

-2014, WARNING: SCARIEST GAME IN YEARS / Five Nights at Freddy's - Part 1, 12 August YouTube, retrieved 26 August 2020 <https://www.youtube.com/watch?v=iOztnsBPrAA>.

Marwick, A.E 2013, Status Update: Celebrity, Publicity, and Branding in the Social Media Age, Yale UP, New Haven.

Mathur, R 2016, 'Your horror game sucks.', 18 July, Gamasutra, retrieved 26 August 2020 <http://www.gamasutra.com/blogs/RaghavMathur/20160718/277253/Your_horror_g ame_sucks.php>.

McGonigal, M 2018, Baldi's Basics in Education and Learning, PC, Micah McGonigal.

McMahan, A 2003, 'Immersion, Engagement, and Presence: A Method for Analyzing 3-D Video Games', in M.J.P Wolf \& B Perron (eds.) The Video Game Theory Reader, Routledge, London - New York, pp. 67-86.

-2008, 'Video Game Stars: Lara Croft', in M.J.P Wolf (ed.), The Video Game Explosion: A History From PONG to PlayStation and Beyond, Greenwood Press, Westport, pp. 183-186.

McRae S 2017, 'Get Off My Internets: How Anti-Fans Deconstruct Lifestyle Bloggers Authenticity Work', Persona Studies, vol. 3, no. 1, pp. 13-27.

Milik, 0 2017, 'Persona in MMO Games: Constructing an Identity Through Complex Player/Character Relationship', Persona Studies, vol. 3, no. 2, pp. 66-78.

Mirzasalikhov, R 2014, One Night, PC, Rinat Mirzasalikhov.

Moore, C, Barbour, K \& Lee, K 2017, 'Five Dimensions of Online Persona', Persona Studies, vol. 3, no. 1, pp. 1-11.

Nephew, M 2006, 'Playing With Identity: Unconscious Desire and Role-Playing Games', in J.P Williams, S.Q Hendricks \& W. Keith Winkler (eds.) Gaming as Culture. Essays on Reality, Identity and Experience in Fantasy Games, McFarland, Jefferson.

Newman, J 2016, 'Stampylongnose and the rise of the celebrity videogame player', Celebrity Studies, vol. 7, no. 2, pp. 285-288, https://doi.org/10.1080/19392397.2016.1165020.

Nguyen, J 2016, 'Performing as Video Game Players in Let's Plays', Transformative Works and Cultures, vol. 22, http://dx.doi.org/10.3983/twc.2016.0698.

NiKyBox 2012, Giochi nel Buio - Penumbra: Black Plague / Ep.1, 27 June, YouTube, retrieved 26 August 2020 <https://www.youtube.com/watch?v=uYZ0RUvpvP8>.

Nintendo 2000, The Legend of Zelda: Majora's Mask, Nintendo 64, Nintendo.

O-Zone 2003, Dragostea Din Tei, DiscO-Zone, Ultra.

Obscure Horror Corner 2015, Sad Satan - Deep Web Horror Game - Part 1, 25 June, YouTube, retrieved 26 August 2020 <https://www.youtube.com/watch?v=tJ6zHUyp_V8>. 
Papale, L \& Fazio, L 2018, 'Player Identity and Avatars in Meta-narrative Video Games: A Reading of Hotline Miami', in R. Rouse, H. Koenitz, M. Haahr (eds.) Interactive Storytelling. ICIDS 2018. Lecture Notes in Computer Science, vol 11318. Springer, Cham. https://doi.org/10.1007/978-3-030-04028-4_28

Parsec Productions 2013, Slender: The Eight Pages, PC, Parsec Productions.

Peck, A 2017, 'Capturing the Slender Man: Online and Offline Vernacular Practice in the Digital Age', Cultural Analysis, vol. 16, no. 1, pp. 30-48.

Perron, B 2005, Coming to Play at Frightening Yourself: Welcome to the World of Horror Games, Aesthetics of Play. A Conference on Computer Game Aesthetics, University of Bergen, Norvège.

-2009, 'Introduction: Gaming After Dark', in Id. (ed.), Horror Video Games. Essays on the Fusion of Fear and Play, McFarland, Jefferson, pp. 3-13.

-2018, The World of Scary Video Games. A study in Videoludic Horror, Bloomsbury, London.

Peters, L 2018, 'Sad Satan' \& The Evolution of Video Game Creepypastas: From "BEN DROWNED" $t$ $o$ "Petscop", 12 February, The Ghost in my Machine, retrieved 26 August $2020<$ https://theghostinmymachine.com/2018/02/12/sad-satan-evolution-videogame-creepypastas-ben-drowned-petscop/>.

PewDiePie 2014, Five Nights At Freddys - SCARIEST GAME EVER!)\#( ๔/\&T!(/YOU)I=O?? (lol no) -, 22 August YouTube, retrieved 26 August $2020<\mathrm{https}$ ://www.youtube.com/watch?v=1r1E-iF2EA>.

-2016, OUTLAST 2 ANIMATED, July, YouTube, retrieved 26 August 2020 $<$ https://www.youtube.com/watch?v=kCh-MMBCI-M>.

Petscop 2017, Petscop, 12 March, YouTube, retrieved 26 August 2020 <https://www.youtube.com/watch?v=6e6RK8o1fcs>.

Pietruszka M 2016, 'Watching people playing games: A survey of presentational techniques in most popular game-vlogs', Res Rhetorica, vol. 4, pp. 54-69.

Pruett, C 2012, Mapping Horror Games, 05 February, Chris's Survival Horror Quest, retrieved 26 August 2020 <http://horror.dreamdawn.com/?p=8335\#widgets>.

Red Barrels 2017, Outlast 2, PlayStation 4, Red Barrels.

Rodríguez Serrano, A 2017, 'La Nada Como Categoría Ontológica En El Videojuego: Análisis De Sad Satan', Fonseca. Journal of Communication, vol. 14, pp. 203-214.

Saunders, B, Sim, J, Kingstone, T, Baker, S, Waterfield, J, Bartlam, B, Burroughs, H \& Jinks, C 2018, 'Saturation in qualitative research: exploring its conceptualization and operationalization', Quality\&Quantity, vol. 52, no. 4, pp. 1893-1907, https://doi.org/10.1007/s11135-017-0574-8.

ShadowLeggy 2006, Resident Evil Numa, 20 December, YouTube, retrieved 26 August 2020 $<$ https://www.youtube.com/watch?v=WMvAzYH1xHM>.

—2007, Resident Evil Excited!, 11 January, YouTube, retrieved 26 August 2020 $<$ https://www.youtube.com/watch?v=3w_E5ZntSM4>.

-2009, Resident Evil Montage Rumble 3.5 - Memes, 20 January, YouTube, retrieved 26 August $2020<$ https://www.youtube.com/watch?v=adeAiaMQoFM>.

SimplexGameStudio (2015) Insanz - Retro Survival Horror, PC, SimplexGameStudio.

Smith, CYN 2017, 'Beware the Slender Man: Intellectual Property and Internet Folklore', Florida Law Review, vol. 70, no. 3, pp. 601-647.

Smith, T, Obrist, M, \& Wright, P 2013, 'Live-streaming changes the (video) game', Proceedings of the 11th european conference on In-teractive TV and video, pp. 131-138.

Smoke The Bear 2018, [FNAF/SFM] My Dear Friend \#4 ROCKSTAR CHICA DANCING CHICKEN (FNAF6/FFPS Animation), 06 July YouTube $<$ https://www.youtube.com/watch?v=8QdPeiHQFlc>

Something Awful 2009, Create Paranormal Images, 08 August, Something Awful Forum, retrieved 26 August $2020<$ https://forums.somethingawful.com/showthread.php?threadid=3150591\&useri $\mathrm{d}=0$ \&perpage $=40$ \&pagenumber $=1>$. 
Suvilay, B 2018, Indie Games. Histoire, artwork, sound design des jeux video indépendants, Bragelonne, Paris.

Team Salvato 2017, Doki Doki Literature Club!, PC, Team Salvato.

TheMeatly Games 2017, Bendy and the Ink Machine, PC, TheMeatly Games.

The Pointers Sisters 1982, I'm So Excited, So Excited!, Planet Records.

TheScarlettears 2009, Let's Play Penumbra Overture - pt1 Intro, 25 June, YouTube, retrieved 26 August $2020<$ https://www.youtube.com/watch?v=6hHhHVaTIAM>.

Tisdale, A 2016, Games we love to watch other people play: Horror gaming and YouTube, 21 December, Ready:Set, retrieved 26 August 2020

<http://readyset.zam.com/article/1272/games-we-love-to-watch-other-people-playhorror-gaming-and-youtube $>$.

Toniolo, F 2020, 'I videogiochi su YouTube: un confronto fra Italia ed estero', in R. Fassone, M.B. Carbone (eds.), Il videogioco in Italia, Mimesis, Milano-Udine, pp. 271-284.

Typhoon Cinema 2015, [Comic Animation] Cute Nights at Freddy's, 18 December, YouTube, retrieved 26 August $2020<\mathrm{https}$ ://www.youtube.com/watch?v=pnaYZUvHsTQ>.

u/BrokenLink100 2015, If you're new to this subreddit, please read this FIRST before posting, 10 July, Reddit, retrieved 26 August

$2020<$ https://www.reddit.com/r/sadsatan/comments/3cslpz/if_youre_new_to_this_su breddit_please_read_this/>.

Waskul, D.D \& Lust, M 2004, 'Role-Playing and Playing Roles: The Person, Player, and Persona in Fantasy Role-Playing', Symbolic Interaction, vol. 27, no. 1, pp. 333-356.

Werning, S 2017, 'The Persona in Autobiographical Game-Making as a Playful Performance of the Self', Persona Studies, vol. 3, no. 1, pp. 28-42.

Yankovic, WA 1999, Albuquerque, Running with Scissors, Volcano.

Zagal, J.P \& Deterding, S 2018 (eds.), Role-Playing Game Studies. Transmedia Foundation, Routledge, London - New York.References presented in Reference style. Hanging format. Single spaced. No space after each entry. Duplicate names marked with M-dash. Follow Referencing Guide on PS website. 